\title{
Iron Lady: A Case of Eosinophilic Fasciitis
}

\author{
Diana Valadares $^{\mathrm{a}, \mathrm{c}}$, Joao Neves ${ }^{\mathrm{a}}$, Isabel Almeida ${ }^{\mathrm{a}}$, Carlos Lopes $^{\mathrm{b}}$, Carlos Vasconcelos ${ }^{\mathrm{a}}$
}

\begin{abstract}
Eosinophilic Fasciitis is a rare rheumatologic disease usually characterized by erythema and limbs' pain, cutaneous induration and peripheral eosinophilia. However, it is important to consider Eosinophilic Fasciitis in differential diagnosis of others sclerodermalike syndromes. The authors present a case of a 52-year-old woman who presented to our hospital with a four months evolution of limb and trunk diffuse symmetrical cutaneous induration, thickening of the skin without joint involvement and no history of Raynaud's phenomenon. On physical examination, she had a grade 3 skin thickening in the involved segments. Laboratory studies revealed no peripheral eosinophilia. The biopsy showed fibrotic involvement of muscle and fascia, with a few inflammatory infiltrations of lymphocytes. She started prednisolone $1 \mathrm{mg} / \mathrm{kg} /$ day, with partial regression of cutaneous injuries. As Eosinophilic Fasciitis is so rare, its recognition can be difficult, especially when the patient is observed at a late stage where the peripheral eosinophilia and inflammatory infiltration in the histology are usually no longer present. A clinical history and a detailed physical examination, especially with the presence of orange peel skin, are the fundamental clues for the diagnosis.
\end{abstract}

Keywords: Eosinophilia Fasciitis; Cutaneous induration; Eosinophilia; Steroids

\footnotetext{
Manuscript accepted for publication January 4, 2011

${ }^{\mathrm{a} C}$ Clinical Immunology Unit, Hospital S. Antonio, Centro Hospitalar do Porto, Portugal

${ }^{\mathrm{b}}$ Pathology Department, Hospital S. Antonio, Centro Hospitalar do Porto, Portugal

${ }^{c}$ Corresponding author: Diana Valadares, Clinical Immunology Unit, Centro Hospitalar do Porto - Hospital Santo Antonio, Largo Prof. Abel Salazar, 4099-001 Porto, Portugal. Email: divaladares@gmail.com
}

doi:10.4021/jmc118w

\section{Introduction}

Eosinophilic Fasciitis (EF) is a rare entity of connective tissue disease. The first description of this disease was made in 1974 by Shulman in a young patient with diffuse fasciitis, hypergammaglobulinemia and eosinophilia [1].

Patients with eosinophilic fasciitis have inflammation and sclerosis of the fascia and subcutaneous tissue of the limbs, which may extend to the trunk, sparing the palms and plants $[2,3]$. The onset of symptoms is usually marked by severe pain and swelling of the extremities with symmetrical induration. Progressively the patient will present orange peel skin with hyperpigmentation that develops to an extreme induration with corky thickening, disabling him in its full mobility.

Visceral involvement is rare on this disease, although some cases are described with pulmonary involvement. Eosinophilic fasciitis is also associated with hematologic malignancies, including lymphoproliferative disease, myelodysplastic syndrome, aplastic anemia, hemolytic anemia, as well as certain drugs (namely statins).

Eosinophilic fasciitis as scleroderma-like syndrome, although uncommon, has an increasingly diverse spectrum of clinical manifestations, not only expressed by skin thickening or edema, making more alluring the diagnosis of this entity.

The diagnosis is based on clinical features and confirmed by skin and/or muscle biopsy showing inflammation, deposition of collagen fibers and lymphocytic infiltration or plasma cells [1-3]. Analytical peripheral eosinophilia, increased sedimentation rate and polyclonal hypergammaglobulinemia could be present.

The differential diagnosis with other entities that present with skin sclerosis and peripheral eosinophilia is essential, such as scleroderma, polymyositis, hypereosinophilic syndrome and Churg-Strauss vasculitis.

Treatment of Eosinophilic Fasciitis is based on corticosteroids at high doses, as described in literature. However, in refractory cases, the use of hydroxychloroquine and immunosuppressants such as cyclosporine or azathioprine are described. 


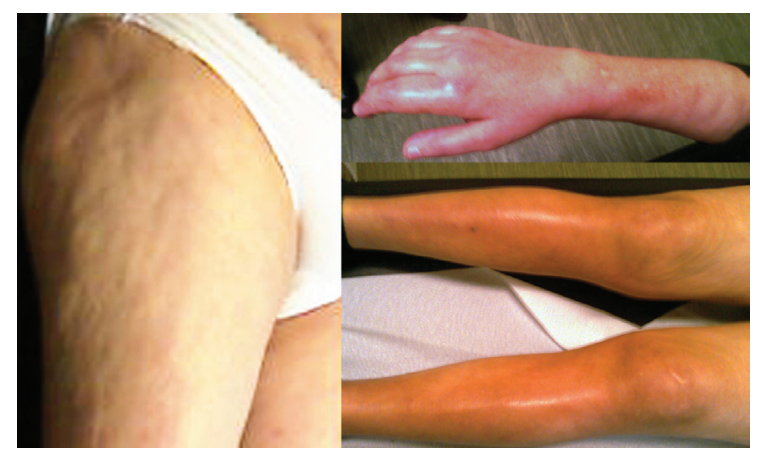

Figure 1. Orange peel skin on the thighs and cutaneous induration and erythema on the superior and inferior limbs.

\section{Case Report}

A 52-year-old woman, without antecedents of relief or chronic medication, presented to our hospital with a four months evolution of diffuse and symmetric cutaneous induration of limbs and trunk, sparing only the fingers. Associately she referred a decreased mobility of the acral skeleton by the skin induration, however without joint involvement. No history of Raynaud's phenomenon or other extra-cutaneous symptoms were reported. Physical examination showed orange peel skin in thighs and grade 3 thickening skin in the upper and lower limbs and trunk (Fig. 1) without sclerodactyly. Laboratory data asserted absence of eosinophilia, increased sedimentation rate and polyclonal hypergammaglobulinemia. Immunological study just revealed a positive antinuclear antibody (1/320) titer. Nailfold capillaroscopy did not show scleroderma pattern. Other diagnostic exams, including chest and abdominal imaging, documented absence of visceral involvement or neoplasia. The patient underwent skin biopsy that showed atrophic epidermis and thickened dermis with fibrosis and little inflammatory activity. Muscle biopsy showed fibrotic involvement of muscle and fascia, with few inflammatory infiltrates (Fig. 2). All the clinical history, analytical and imagiological data corroborated the diagnosis of eosinophilic fasciitis, therefore the patient started prednisolone $1 \mathrm{mg} / \mathrm{kg} /$ day, with partial regression of skin lesions. Twelve months after the beginning of this treatment, the patient achieved full mobility to perform all basic tasks, such as dressing and eating. At the moment, she presents a normal skin on the trunk and thighs and maintains grade 3 skin thickening on the legs and grade 2 on upper limbs, and with analytically normalized inflammatory parameters. The patient is still taking a low dose of corticosteroids without any intercurrence.

\section{Discussion}

The pathogenesis of Eosinophilic Fasciitis is not totally clarified, however it is based on an exaggerated immune response in an intense pro-inflammatory environment. Many times, it's possible to identify a "trigger" that causes this entire cascade. It is described in the literature its association with trauma, strong physical exercise and some infections, but its reproducibility is poor [4].

Eosinophilic Fasciitis is a rare disease and its diagnosis is not always easy. The skin sclerosis is a common manifestation to several diseases, including the scleroderma (systemic and local) and scleroderma-like syndromes. Eosinophilic Fasciitis or Shulman syndrome should be part of differential diagnosis in the management of these patients. Thus the combination of clinical history with physical examination findings, such as symmetrical induration of the skin, swelling, pain or redness associated with peripheral eosinophilia, and aided by a muscle or skin biopsy, allowed us to confirm the definitive diagnosis of Eosinophilic Fasciitis.

Eosinophilic Fasciitis is a disease which appears initially with erythema and edema of the members associated with cutaneous induration that progressively limits the patients' mobility. In the initial phase of the disease, peripheral eosinophilia and infiltration of skin and muscle are usually present. However, when the patient seeks medical help very late, eosinophilic blood count is normal and the tissue in-

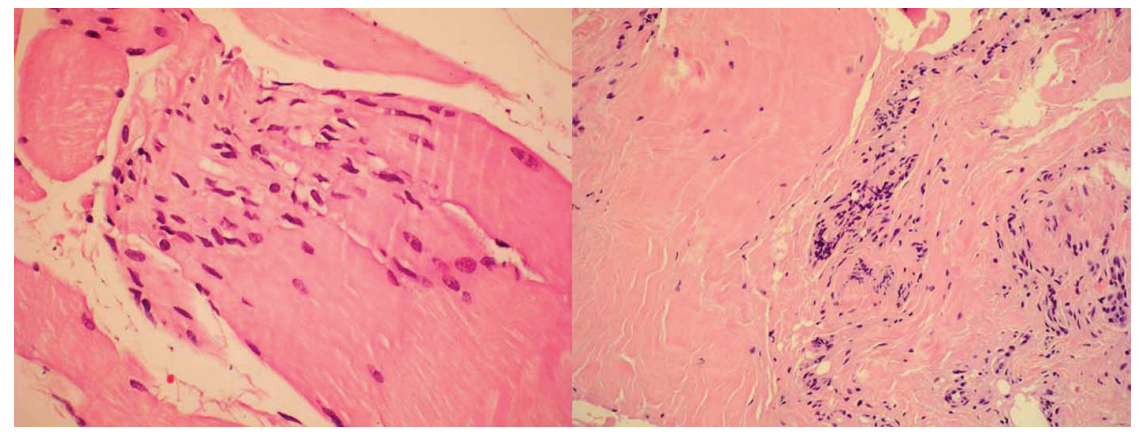

Figure 2. Muscular biopsy showing sclerosis and lymphocytic infiltration. 
filtration is rare, usually showing sclerosis and lymphocytic infiltration [5-7].

The imaging methods are more and more precious in clinical diagnosis. The biopsy of the skin or muscle tissue is essential, although, actually Magnetic Resonance Imaging (MRI) of soft tissues has played a major role in assisting the diagnosis of this disease, not only for monitoring the disease, but also to assess the most appropriate place for biopsy [8, 9]. MRI of the lower limbs in T1 and T2 weighted with gadolinium injection may show diffuse thickening of the inflammatory nature of the muscle fascia, as well as the preservation of hypersignal of the muscles in the absence of myositis [10-12]. The patient in our clinical case was not submitted to this diagnostic exam because it wasn't available in utility time compared with the biopsy. This imaging method is being used increasingly as an instrument of great accuracy for the diagnosis of Eosinophilic Fasciitis. It contains specific alterations of this disease and will be very important in the differential diagnosis of other scleroderma-like diseases.

Steroid therapy is the first line treatment of this disease as the main aim is the resolution of fibrotic manifestations in the tissues. Treatment with prednisolone or its equivalent should be initiated with doses of $0.5-1 \mathrm{mg} / \mathrm{kg} /$ day that should be maintained until clinical improvement and decreased slowly until the complete clinical remission. In some cases, where the disease is more aggressive at presentation, with particular involvement of skin of the neck, trunk or a consumptive board, the dosage of corticosteroids should be greater or a combination of immunosuppressive agents should be done $[4,6]$. The use of immunosuppressants such as methotrexate, cyclosporine, and azathioprine has been proven its effectiveness in cases of corticosteroid resistance [13]. In recent studies, the use of infliximab during 8 weeks induced clinical remission in patients during $1-3$ years $[14,15]$.

\section{References}

1. Bischoff L, Derk CT. Eosinophilic fasciitis: demographics, disease pattern and response to treatment: report of 12 cases and review of the literature. Int J Dermatol 2008;47(1):29-35.

2. Foti R, Leonardi R, Rondinone R, Di Gangi M, Leonetti C, Canova M, Doria A. Scleroderma-like disorders. Autoimmun Rev 2008;7(4):331-339.

3. Endo Y, Tamura A, Matsushima Y, Iwasaki T, Hasegawa M, Nagai Y, Ishikawa O. Eosinophilic fasciitis: report of two cases and a systematic review of the literature dealing with clinical variables that predict outcome. Clin Rheumatol 2007;26(9):1445-1451.

4. Boin F, Hummers LK. Scleroderma-like fibrosing disorders. Rheum Dis Clin North Am 2008;34(1):199-220; ix.

5. Naoui A, Bouslama K, Abdallah M, Hamzaoui S, Arbi T, Bahri F, M'Zabi S, et al. [Eosinophilic fasciitis (Shulman's disease): a case series of 11 patients]. Rev Med Interne 2010;31(8):535-539.

6. Danis R, Akbulut S, Altintas A, Ozmen S, Ozmen CA. Unusual presentation of eosinophilic fasciitis: two case reports and a review of the literature. J Med Case Reports 2010;4:46.

7. Falcao S, Mourao AF, Ribeiro C, Pinto TL, Mateus M, Araujo P, Nero P, et al. [Eosinophilic fasciitis and aplastic anemia]. Acta Reumatol Port 2009;34(1):120-126.

8. Baumann F, Bruhlmann P, Andreisek G, Michel BA, Marincek B, Weishaupt D. MRI for diagnosis and monitoring of patients with eosinophilic fasciitis. AJR Am J Roentgenol 2005;184(1):169-174.

9. Moulton SJ, Kransdorf MJ, Ginsburg WW, Abril A, Persellin S. Eosinophilic fasciitis: spectrum of MRI findings. AJR Am J Roentgenol 2005;184(3):975-978.

10. Agnew KL, Blunt D, Francis ND, Bunker CB. Magnetic resonance imaging in eosinophilic fasciitis. Clin Exp Dermatol 2005;30(4):435-436.

11. Liou CH, Huang GS, Taylor JA, Juan CJ, Gao HW, Chen CY. Eosinophilic fasciitis in a military recruit: MRI evaluation with clinical correlation. Skeletal Radiol 2003;32(1):52-57.

12. Desvignes-Engelbert A, Sauliere N, Loeuille D, Blum A, Chary-Valckenaere I. Polymyalgia revealing eosinophilic fasciitis in a young male: Contribution of magnetic resonance imaging. Joint Bone Spine 2010;77(4):367368.

13. Silny W, Osmola-Mankowska A, Czarnecka-Operacz M, Zaba R, Danczak-Pazdrowska A, Marciniak A. Eosinophilic fascitis: a report of two cases treated with ultraviolet A1 phototherapy. Photodermatol Photoimmunol Photomed 2009;25(6):325-327.

14. Khanna D, Agrawal H, Clements PJ. Infliximab may be effective in the treatment of steroid-resistant eosinophilic fasciitis: report of three cases. Rheumatology (Oxford) 2010;49(6):1184-1188.

15. Tzaribachev N, Holzer U, Schedel J, Maier V, Klein R, Kuemmerle-Deschner J. Infliximab effective in steroiddependent juvenile eosinophilic fasciitis. Rheumatology (Oxford) 2008;47(6):930-932. 